\title{
OPEN The macroscopic shape of assemblies formed from microparticles based on host-guest interaction dependent on the guest content
}

\author{
Takahiro Itami ${ }^{1}$, Akihito Hashidzume ${ }^{1 \bowtie}$, Yuri Kamon ${ }^{1}$, Hiroyasu Yamaguchi ${ }^{1}$ \& \\ Akira Harada ${ }^{2 \bowtie}$
}

Biological macroscopic assemblies have inspired researchers to utilize molecular recognition to develop smart materials in these decades. Recently, macroscopic self-assemblies based on molecular recognition have been realized using millimeter-scale hydrogel pieces possessing molecular recognition moieties. During the study on macroscopic self-assembly based on molecular recognition, we noticed that the shape of assemblies might be dependent on the host-guest pair. In this study, we were thus motivated to study the macroscopic shape of assemblies formed through host-guest interaction. We modified crosslinked poly(sodium acrylate) microparticles, i.e., superabsorbent polymer (SAP) microparticles, with $\beta$-cyclodextrin $(\beta C D)$ and adamantyl (Ad) residues $(\beta C D(x)$-SAP and $\operatorname{Ad}(y)$-SAP microparticles, respectively, where $x$ and $y$ denote the mol\% contents of $\beta C D$ and Ad residues). Then, we studied the self-assembly behavior of $\beta C D(x)$-SAP and Ad(y)-SAP microparticles through the complexation of $\beta C D$ with Ad residues. There was a threshold of the $\beta C D$ content in $\beta C D(x)$-SAP microparticles for assembly formation between $x=22.3$ and 26.7. On the other hand, the shape of assemblies was dependent on the Ad content, $y$; More elongated assemblies were formed at a higher $y$. This may be because, at a higher $y$, small clusters formed in an early stage can stick together even upon collisions at a single contact point to form elongated aggregates, whereas, at a smaller $y$, small clusters stick together only upon collisions at multiple contact points to give rather circular assemblies. On the basis of these observations, the shape of assembly formed from microparticles can be controlled by varying $y$.

Biological systems utilize macroscopic self-assemblies based on molecular recognition. In these decades, biological macroscopic assemblies have inspired researchers to utilize molecular recognition to develop smart materials $^{1-3}$, e.g., soft actuators ${ }^{4-9}$ and self-healing materials ${ }^{10-25}$. Recently, macroscopic self-assemblies, which allow ones to see molecular recognition by naked eyes, have been realized using millimeter-scale hydrogel pieces possessing molecular recognition moieties ${ }^{26-30}$. Even if the difference in binding constants of molecular recognition moieties is small, the systems of mixture of gel pieces can exhibit perfect fidelity by controlling the contents of molecular recognition moieties ${ }^{31-33}$. During the study on macroscopic self-assembly based on molecular recognition, we noticed that the shape of assemblies might be dependent on the host-guest pair; For example, the pair of $\beta$-cyclodextrin ( $\beta C D$ ) and adamantyl (Ad), which shows one of the highest binding constants, led to the formation of linear alternating assemblies, whereas $\beta C D$ and $t$-butyl, which possesses a lower binding constant, might form planar checkered assemblies ${ }^{26}$. We were thus motivated to study the macroscopic shape of assemblies formed through host-guest interaction. We have chosen crosslinked poly(sodium acrylate) microparticles, i.e., superabsorbent polymer (SAP) microparticles, because of the availability and ease of modification. We have employed a combination of $\beta \mathrm{CD}$ and $\mathrm{Ad}$ as host and guest residues, respectively, because this combination forms stable inclusion complexes. In the present article, we describe preparation of SAP microparticles modified with

\footnotetext{
${ }^{1}$ Graduate School of Science, Osaka University, 1-1 Machikaneyama-cho, Toyonaka, Osaka 560-0043, Japan. ${ }^{2}$ The Institute of Scientific and Industrial Research, Osaka University, 8-1 Mihogaoka, Ibaraki, Osaka 567-0047, Japan. ${ }^{\circledR}$ email: hashidzume@chem.sci.osaka-u.ac.jp; harada@chem.sci.osaka-u.ac.jp
} 
$\beta C D$ and Ad residues $(\beta C D(x)$-SAP and Ad $(y)$-SAP microparticles, respectively, where $x$ and $y$ denote the mol\% contents of $\beta C D$ and Ad residues), and the self-assembly behavior of $\beta C D(x)$-SAP and $\operatorname{Ad}(y)$-SAP microparticles through the complexation of $\beta C D$ with Ad residues, and discuss the effect of the contents of residues, i.e., $x$ and $y$, on the self-assembly behavior.

\section{Results}

Preparation of superabsorbent polymer microparticles modified with $\beta$-cyclodextrin and adamantyl residues. We employed 10SH-NF SAP microparticles (Sumitomo Seika Chemicals Co., Ltd.) as a scaffold in this study, not only because the particles are rather spherical and uniform in size but also because the swollen SAP microparticles should be soft enough for interaction. The SAP microparticles were modified with $\beta$-cyclodextrin $(\beta C D)$ and adamantyl $(\mathrm{Ad})$ residues $(\beta \mathrm{CD}(x)$-SAP and $\operatorname{Ad}(y)$-SAP microparticles, respectively, where $x$ and $y$ denote the mol\% contents of $\beta C D$ and Ad residues) by coupling of mono-(6-amino-6deoxy)- $\beta$-CD $\left(\beta C D-\mathrm{NH}_{2}\right)$ and 1-adamantanamine hydrochloride $\left(\mathrm{Ad}-\mathrm{NH}_{2} \cdot \mathrm{HCl}\right)$ with carboxylic acid residues in SAP microparticles using 4-(4,6-dimethoxy-1,3,5-triazin-2-yl)-4-methylmorpholinium chloride $n$-hydrate (DMT-MM) as a coupling agent (Fig. 1a). The $\beta C D(x)$-SAP and $\operatorname{Ad}(y)$-SAP microparticles were purified by washing repeatedly with water for a few days. The $\beta \mathrm{CD}(x)$-SAP and $\operatorname{Ad}(y)$-SAP microparticles prepared were characterized by solid-state ${ }^{1} \mathrm{H}$ field gradient magic angle spinning (FGMAS) NMR and attenuated total reflectance (ATR) FT/IR spectroscopy (Fig. S1 and S2 in Supporting Information, respectively). As can be seen in Fig. S1, the ${ }^{1} \mathrm{H}$ FGMAS NMR spectra exhibited signals ascribable to $\beta C D$ and Ad residues for $\beta C D(x)$-SAP and $\operatorname{Ad}(y)$-SAP microparticles at 5.32 and $1.64 \mathrm{ppm}$, respectively. As shown in Fig. S2, the ATR FT/IR spectra contain absorption bands ascribable to the stretching vibration of $\mathrm{C}=\mathrm{O}$ of the amide bond at $\mathrm{ca} .1650 \mathrm{~cm}^{-1}$. These spectra are indicative of successful modification of SAP microparticles.

In this study, the contents of $\beta C D$ and $\operatorname{Ad}$ residues in $\beta C D(x)$-SAP and $\operatorname{Ad}(y)$-SAP microparticles, $x$ and $y$, are important parameters, but it was not possible to determine the contents of $\beta C D$ and Ad residues of SAP microparticles by ${ }^{1} \mathrm{H}$ FGMAS NMR because of lack of quantitativity. Thus, the values of $x$ and $y$ were roughly estimated by the weights of remaining $\beta \mathrm{CD}-\mathrm{NH}_{2}$ and $\mathrm{Ad}-\mathrm{NH}_{2} \cdot \mathrm{HCl}$ recovered from the reaction mixtures, as listed in Tables 1 and 2. The $\beta C D$ and $\operatorname{Ad}$ contents in $\beta C D(x)$-SAP and $\operatorname{Ad}(y)$-SAP microparticles are markedly lower than those in feed. It should be noted here that the differences in contents are much larger for the $\operatorname{Ad}(y)$-SAP microparticles than those for $\beta \mathrm{CD}(x)$-SAP microparticles. This may be caused by the difference in reactivities of $\beta C D-\mathrm{NH}_{2}$ and $\mathrm{Ad}-\mathrm{NH}_{2} \cdot \mathrm{HCl}$. $\beta \mathrm{CD}-\mathrm{NH}_{2}$ is an amine, whereas $\mathrm{Ad}-\mathrm{NH}_{2} \cdot \mathrm{HCl}$ is an ammonium. The hydrochloride, Ad- $\mathrm{NH}_{2} \cdot \mathrm{HCl}$, was used because of the low solubility of 1-adamantanamine in water. The $\mathrm{pH}$ values of reaction media were thus different for modification with $\beta C D$ and Ad residues; $\mathrm{pH}=8.1$ and 6.3 for $\beta C D$ and Ad residues, respectively. Since, in amide coupling reactions using DMT-MM, the 4,6-dimethoxy-1,3,5-triazine residue is attacked by a carboxylate ion, the coupling proceeds less efficiently at lower $\mathrm{pH}^{34}$. Therefore, the lower $\mathrm{pH}$ upon modification with Ad residues may be partly responsible for the reduced Ad contents in $\operatorname{Ad}(y)$-SAP microparticles. It should be also noted that SAP microparticles exhibited different adsorption properties for $\beta C D-\mathrm{NH}_{2}$ and Ad- $\mathrm{NH}_{2} \cdot \mathrm{HCl}$. The affinities of SAP microparticles for $\beta \mathrm{CD}-\mathrm{NH}_{2}$ and $\mathrm{Ad}-\mathrm{NH}_{2} \cdot \mathrm{HCl}$ were compared by adsorption experiments. SAP microparticles fully swollen with water $(2.0 \mathrm{~g})$ were added to an aqueous solution of $\beta \mathrm{CD}-\mathrm{NH}_{2}$ or Ad- $\mathrm{NH}_{2} \cdot \mathrm{HCl}(5.0 \mathrm{mM}, 10 \mathrm{~mL})$. After equilibration, the concentration of solute, i.e., $\beta C D-\mathrm{NH}_{2}$ or $\mathrm{AdNH} \mathrm{H}_{2} \cdot \mathrm{HCl}$, and the volumes of aqueous solution and SAP microparticles were determined. Using these data, the amounts of $\beta \mathrm{CD}-\mathrm{NH}_{2}$ and $\mathrm{Ad}-\mathrm{NH}_{2} \cdot \mathrm{HCl}$ adsorbed were evaluated to be ca. 52 and $2.3 \mathrm{mg}$ (45 and $12 \mu \mathrm{mol}$ ), respectively, per $1 \mathrm{~g}$ of SAP microparticles, indicating that $\beta \mathrm{CD}-\mathrm{NH}_{2}$ is adsorbed into SAP microparticles more strongly than Ad- $\mathrm{NH}_{2} \cdot \mathrm{HCl}$. This may be because $\mathrm{Ad}-\mathrm{NH}_{2} \cdot \mathrm{HCl}$ was salted out more readily than $\beta \mathrm{CD}-\mathrm{NH}_{2}$ because of its hydrophobicity and concentrated $\mathrm{Na}^{+}$ions inside the SAP microparticles. It is thus likely that $\beta \mathrm{CD}$ residues were introduced efficiently not only to carboxylate residues on the surface of SAP microparticles but also to those inside of SAP microparticles, whereas Ad residues were introduced dominantly to carboxylate residues on the outer layer of SAP microparticles.

The average diameters $\left(D_{\text {av }}\right)$ for a hundred of $\beta \operatorname{CD}(x)$-SAP and $\operatorname{Ad}(y)$-SAP microparticles fully swollen with water were determined by observing on an optical microscope. Values of $D_{\mathrm{av}}$ were plotted in Fig. 1b against the $\beta C D$ or Ad content, i.e., $x$ or $y$. The $D_{\text {av }}$ values (ca. $\left.100 \mu \mathrm{m}\right)$ for $\beta C D(x)$-SAP microparticles were significantly smaller than that for unmodified SAP microparticles, whereas the $D_{\text {av }}$ values $($ ca. $190 \mu \mathrm{m})$ for $\operatorname{Ad}(y)$-SAP microparticles were almost the same as that for SAP microparticles independent of $y$. The smaller $D_{\text {av }}$ values for $\beta C D(x)$-SAP microparticles indicate that $\beta C D$ residues in $\beta C D(x)$-SAP microparticles interact with each other or with carboxylate residues presumably through hydrogen bonding formation ${ }^{35,36}$, resulting in a reduced swelling ratio of microparticles. These observations may support the different fashions of modification for $\beta C D$ and Ad residues.

For visual discrimination, dyeing of $\operatorname{Ad}(y)$-SAP microparticles was tested using several dyes. The food pigments, which we had used for poly(acrylamide)-based gels in our previous studies ${ }^{26,27,31-33}$, were not useful in this study because the pigment molecules quickly came out of $\operatorname{Ad}(y)$-SAP microparticles. The results of dyeing test indicated that pararosaniline was a useful dye presumably because of electrostatic interaction between the ammonium in pararosaniline and carboxylate residues in $\operatorname{Ad}(y)$-SAP microparticles (Fig. 1c). Under the dyeing conditions in this study, the size distributions of $\operatorname{Ad}(y)$-SAP microparticles were almost the same before and after dyeing (data not shown). It is thus likely that pararosaniline has no effect on the properties of $\operatorname{Ad}(y)$-SAP microparticles and on the interaction of $\beta \operatorname{CD}(x)$-SAP and $\operatorname{Ad}(y)$-SAP microparticles. In the following, $\operatorname{Ad}(y)$-SAP microparticles dyed with pararosaniline were used; Colorless and red particles are $\beta C D(x)$-SAP and $\operatorname{Ad}(y)$-SAP microparticles, respectively. 
(a)

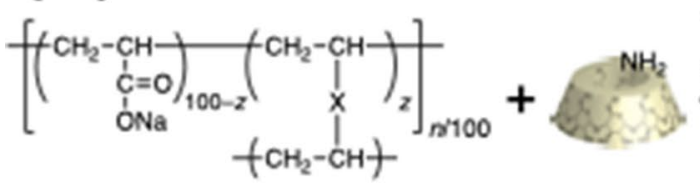

$\beta C D-\mathrm{NH}_{2}$

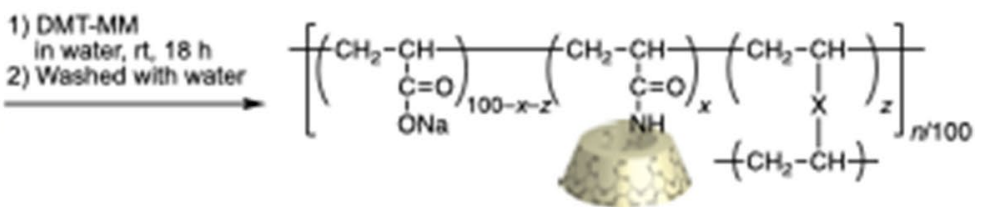

$\beta C D(x)$-SAP

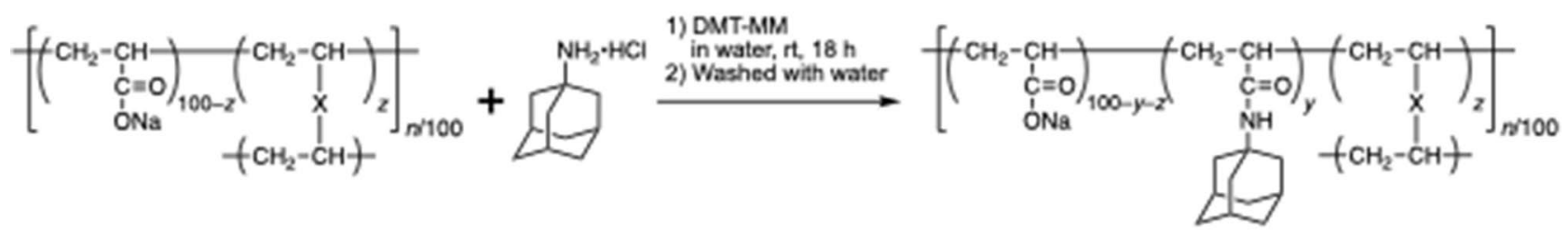

SAP

\section{(b)}

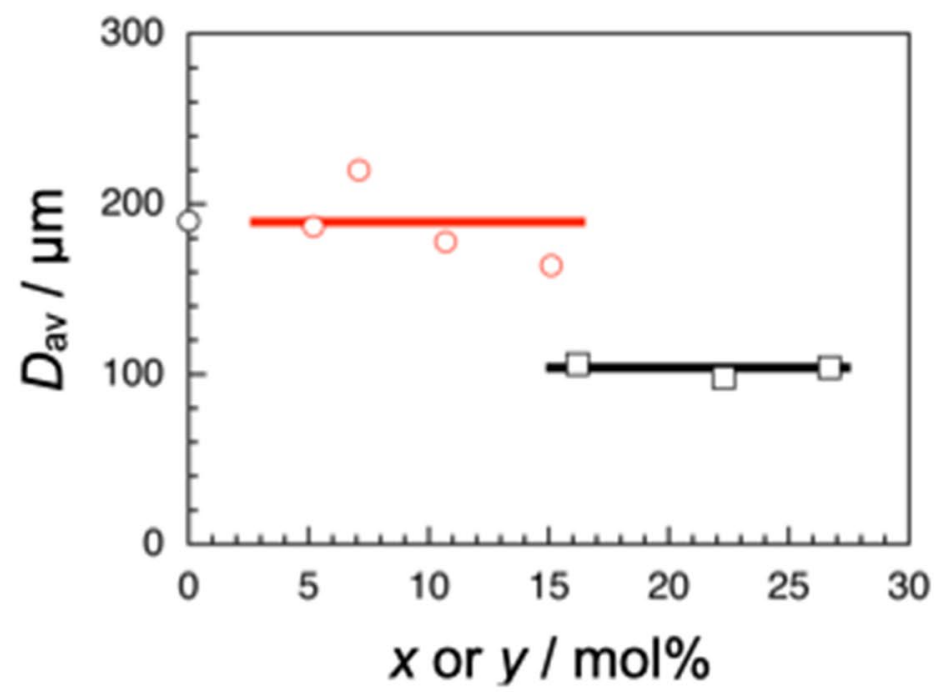

(c)
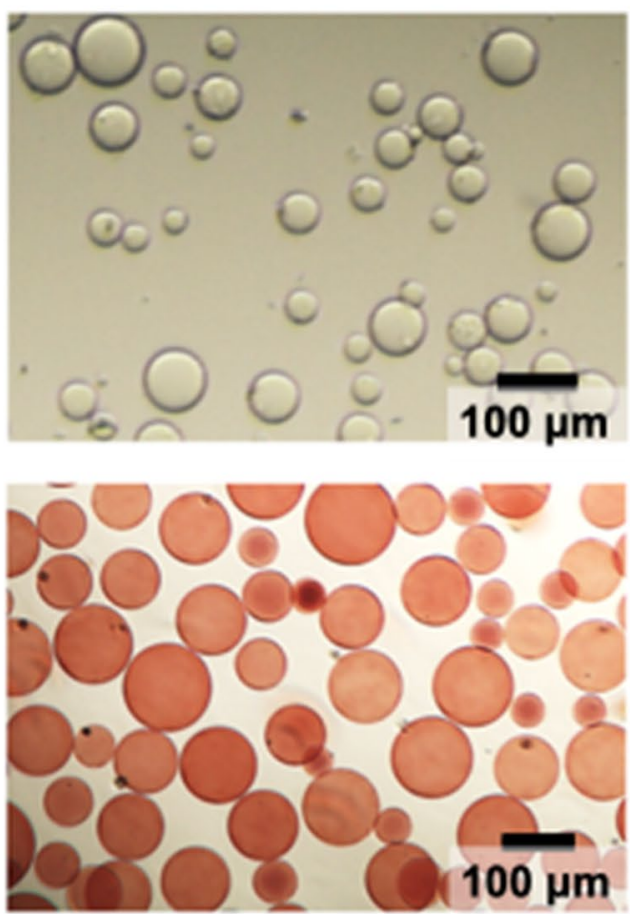

Figure 1. Preparation of $\beta C D(x)$-SAP and $\operatorname{Ad}(y)$-SAP microparticles. (a) Synthetic scheme of $\beta C D(x)$-SAP and $\operatorname{Ad}(y)$-SAP microparticles. (b) The average diameter $\left(D_{\mathrm{av}}\right)$ as a function of $x$ or $y$ for the unmodified SAP (black circle), $\beta C D(x)$-SAP (black square) and Ad $(y)$-SAP microparticles (red circle). (c) A typical example of optical micrographs for $\beta \mathrm{CD}(26.7)$-SAP (colorless) and Ad(15.1)-SAP microparticles (red).

\begin{tabular}{|l|l|l|l|l|}
\hline Feed $(\mathbf{m o l} \%)$ & Native-SAP/mg $(\mathbf{C O O H}$ unit/mmol $)$ & $\boldsymbol{\beta C D}_{-} \mathbf{N H}_{2} / \mathbf{m g}(\mathbf{m m o l})$ & $\mathbf{D M T}-\mathbf{M M} / \mathbf{m g}(\mathbf{m m o l})$ & $\boldsymbol{x}(\mathbf{m o l} \%)$ \\
\hline 30 & $10.1(0.179)$ & $60.7(0.053)$ & $22.3(0.081)$ & 16.2 \\
\hline 40 & $10.2(0.180)$ & $81.2(0.072)$ & $30.0(0.107)$ & 22.3 \\
\hline 100 & $10.1(0.179)$ & $203.6(0.179)$ & $74.5(0.270)$ & 26.7 \\
\hline
\end{tabular}

Table 1. Conditions and results of preparation of $\beta C D(x)$-SAP microparticles. 


\begin{tabular}{|l|l|l|l|l|}
\hline Feed $(\mathbf{m o l} /)$ & Native-SAP/mg $(\mathbf{C O O H}$ unit/mmol) & Ad- $\mathbf{N H}_{2} \cdot \mathbf{H C l} / \mathbf{m g}(\mathbf{m m o l})$ & DMT-MM/mg (mmol) & $y$ (mol\%) \\
\hline 10 & $10.0(0.178)$ & $3.4(0.018)$ & $7.5(0.027)$ & 5.2 \\
\hline 30 & $10.2(0.180)$ & $10.2(0.053)$ & $22.3(0.081)$ & 7.1 \\
\hline 50 & $10.0(0.180)$ & $16.8(0.090)$ & $37.1(0.13)$ & 10.7 \\
\hline 200 & $10.2(0.180)$ & $67.0(0.36)$ & $149(0.54)$ & 15.1 \\
\hline
\end{tabular}

Table 2. Conditions and results of preparation of $\operatorname{Ad}(y)$-SAP microparticles.

Interaction of $\beta C D(x)$-SAP and $A d(y)$-SAP microparticles. The interaction of $\beta C D(x)$-SAP and $\operatorname{Ad}(y)$-SAP microparticles was investigated by observing on an optical microscope. A suspension containing ca. $50 \beta \mathrm{CD}(x)$-SAP microparticles in water $(1 \mu \mathrm{L})$ and a suspension containing ca. $50 \mathrm{Ad}(y)$-SAP microparticles in water $(1 \mu \mathrm{L})$ were mixed on a clean slide glass. Since the SAP microparticles used in this study did not undergo practically Brownian motion because of their larger size, the mixed suspension was preliminarily agitated using tweezers. As can be seen in Movie S1 in Supporting Information, $\beta C D(26.7)$-SAP and Ad(15.1)-SAP microparticles adhered to each other to form an assembly. For reproducibility, the interaction studies were further carried out by agitation at $500 \mathrm{rpm}$ using a mixer. Typical examples of assemblies formed are shown in Fig. $2 \mathrm{a}$. Here the circles inside some microparticles were bubbles, which could not be removed. The results of interaction are summarized in Table S1 in Supporting Information. In this table, “-” denotes no assembly formation from $\beta \mathrm{CD}(x)$-SAP and $\operatorname{Ad}(y)$-SAP microparticles, and "+" denotes the formation of assemblies from microparticles. $\beta C D(x)$-SAP microparticles of $x=16.2$ or 22.3 did not adhere to any of the $\operatorname{Ad}(y)$-SAP microparticles used in this study, indicating that the number of $\beta C D$ residues on the surface of $\beta \mathrm{CD}(x)$-SAP microparticles of $x=16.2$ or 22.3 was not enough for assembly formation with the $\operatorname{Ad}(y)$-SAP microparticles. At $x=16.2$ and 22.3, the electrostatic repulsion between carboxylate ions of $\beta \mathrm{CD}(x)$-SAP and $\operatorname{Ad}(y)$-SAP microparticles may dominate over the attractive interaction of $\beta C D$ and Ad residues. On the other hand, $\beta C D(26.7)$-SAP microparticles interacted with all the $\operatorname{Ad}(y)$-SAP microparticles examined to form assemblies. These observations indicate that there is a threshold of the $\beta C D$ content in $\beta C D(x)$-SAP microparticles for assembly formation between $x=22.3$ and 26.7.

The interaction of $\beta \mathrm{CD}(26.7)$-SAP and $\operatorname{Ad}(y)$-SAP microparticles was also investigated in the presence of competitors, i.e., $\beta C D$ and sodium 1-adamantanecarboxylate (AdC). When $\beta C D(26.7)$-SAP and $\operatorname{Ad}(15.1)$-SAP microparticles were agitated in water on a glass plate at $500 \mathrm{rpm}$ for $1 \mathrm{~min}$ in the presence of $0.60 \mathrm{mM} \beta C D$ or $0.20 \mathrm{mM}$ AdC, no assemblies were formed. Since $\beta C D$ molecules include Ad residues in Ad(15.1)-SAP microparticles, and AdC molecules are included in $\beta C D$ residues in $\beta C D(26.7)$-SAP microparticles in these experiments, $\beta C D$ or Ad residues on microparticles are masked, resulting in no assembly formation. These observations confirm that the formation of assemblies from $\beta \mathrm{CD}(26.7)$-SAP and $\operatorname{Ad}(y)$-SAP microparticles is based on the formation of inclusion complexes of $\beta C D$ and Ad residues on the surface of SAP microparticles.

The interaction of $\beta C D(26.7)$-SAP and $\operatorname{Ad}(y)$-SAP microparticles was also examined in the presence of varying concentrations of the competitors, i.e., $\beta \mathrm{CD}$ and AdC. In the presence of lower concentrations of the competitor, two or more assemblies were formed from fewer $\beta \mathrm{CD}(26.7)$-SAP and $\operatorname{Ad}(y)$-SAP microparticles. The total numbers $(N)$ of microparticles forming assemblies were counted. The experiments were repeated three times under the same conditions to obtain the average $N$ values. The $N$ values were plotted in Fig. $2 \mathrm{~b}$ against the competitor concentration $([\beta C D]$ or $[\mathrm{AdC}])$. The dependencies of $N$ on the competitor concentration are practically the same at a $y$ independent of the species of competitor. As the competitor concentration increases, $N$ decreases rapidly and reaches unity, i.e., no assembly formation, in the region of $10^{-1}-10^{0} \mathrm{mM}$. It should be noted here that $N$ values at lower competitor concentrations are larger at higher $y$. This observation indicates that the interaction of $\beta \mathrm{CD}(26.7)$-SAP and $\mathrm{Ad}(y)$-SAP microparticles is stronger at higher $y^{37}$.

As can be seen in Fig. 2a, the shape of assemblies seems to be dependent on the Ad content, $y$. The assembly formed at $y=15.1$ shows a more elongated shape than does that formed at $y=5.2$. Thus, the largest assembly formed by agitating $\beta C D(26.7)-S A P$ and $\operatorname{Ad}(y)$-SAP microparticles of each $y$ at $500 \mathrm{rpm}$ (Fig. 3a) was analyzed by ellipse fit using an ImageJ software ${ }^{38}$ to evaluate the aspect ratio $(a / b$, where $a$ and $b$ are the longer and shorter axes, respectively). The same experiments were repeated three times, and the average value of $a / b$ was calculated. Figure $3 \mathrm{~b}$ demonstrates the aspect ratio, $a / b$, as a function of the Ad content, $y$. The aspect ratio, $a / b$, increases from ca. 1.5 to ca. 2.8 with increasing $y$ from 5.2 to 15.1 . These observations indicate that assemblies of a larger aspect ratio are formed at a higher $y$, i.e., upon stronger interaction.

\section{Discussion}

As can be seen in Fig. 3b, there is a remarkable correlation between the Ad content $(y)$ in $\operatorname{Ad}(y)$-SAP microparticles and the aspect ratio $(a / b)$ of assemblies formed from $\beta \mathrm{CD}(26.7)$-SAP and $\operatorname{Ad}(y)$-SAP microparticles. In the assemblies, the interaction between $\beta \mathrm{CD}(26.7)$-SAP and $\mathrm{Ad}(y)$-SAP microparticles is stronger at higher $y$ because of the larger number of inclusion complexes of $\beta C D$ and Ad residues in a contact region. The correlation between $y$ and $a / b$ can be roughly explained as follows. Since the attractive interaction between $\beta C D(26.7)$-SAP and $\operatorname{Ad}(y)$-SAP microparticles of a larger $y$ is strong enough, small clusters formed in an early stage can stick together even upon collisions at a single contact point, resulting in the formation of elongated aggregates. On the other hand, at a smaller $y$, small clusters stick together only upon collisions at multiple contact points, leading to rather circular assemblies.

Although the $\beta \mathrm{CD}(x)$-SAP and $\operatorname{Ad}(y)$-SAP microparticles are non-Brownian particles, the formation of assemblies from the microparticles is similar to aggregation of colloidal particles which undergo Brownian 
(a)
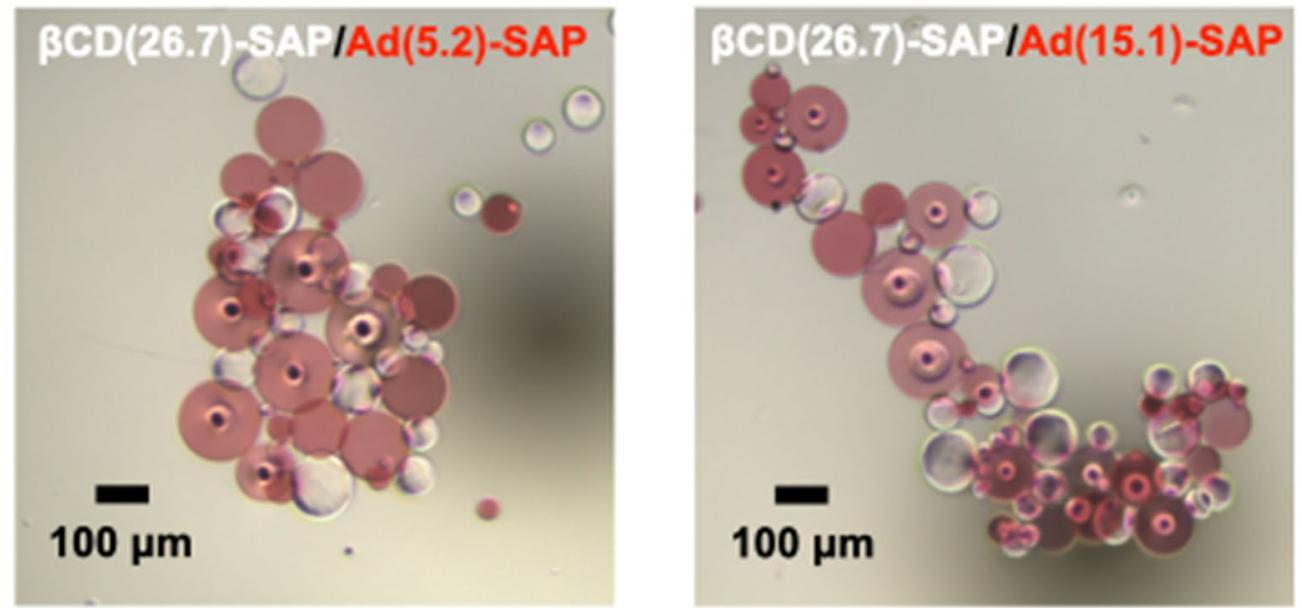

(b)
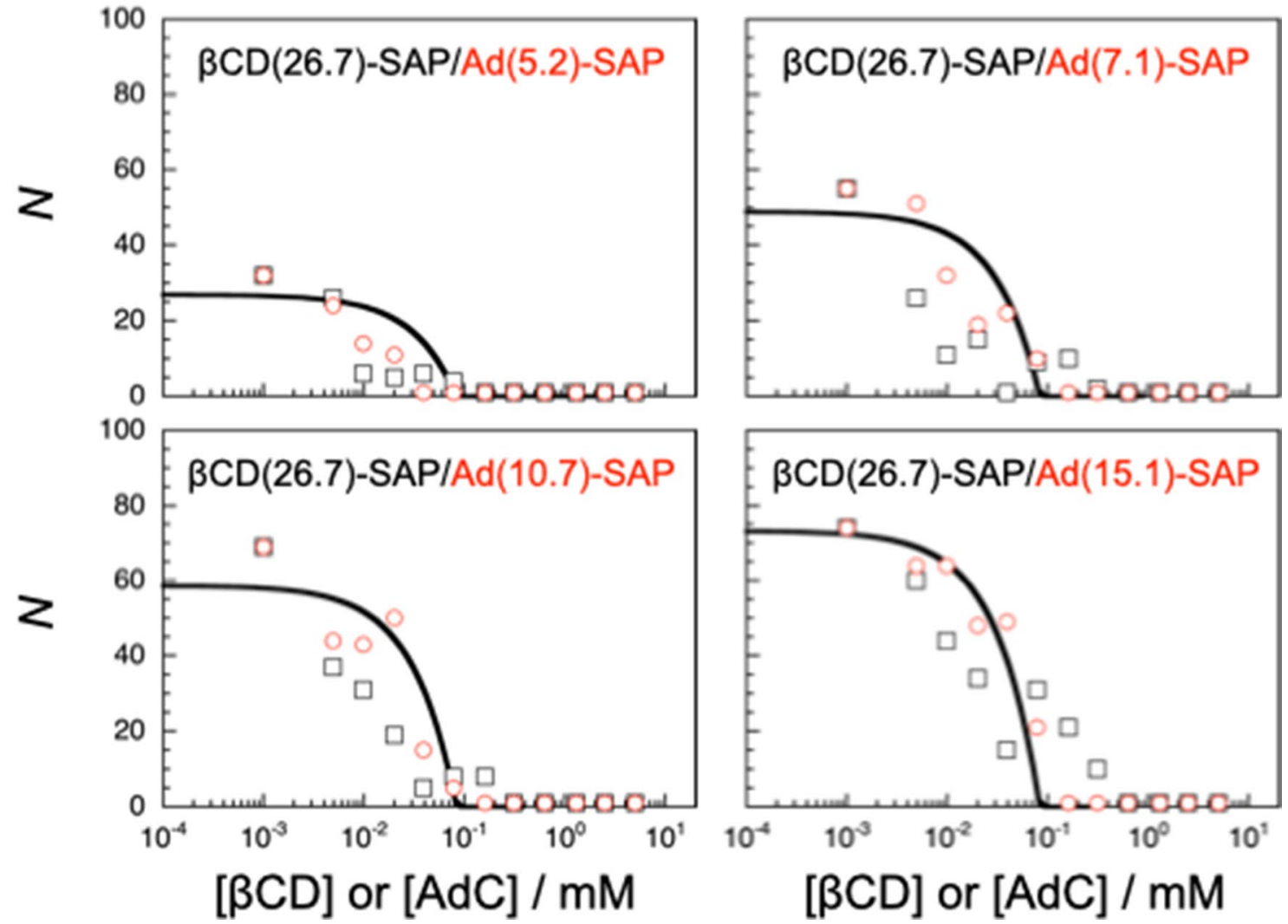

Figure 2. Interaction of $\beta C D(26.7)$-SAP and $A d(y)$-SAP microparticles. (a) A typical example of optical micrographs for assemblies formed from $\beta C D(26.7)$-SAP and Ad(5.2)-SAP microparticles, and from $\beta C D(26.7)$-SAP and Ad(15.1)-SAP microparticles. (b) The number $(N)$ of SAP particles in $\beta C D(26.7)-S A P /$ $\operatorname{Ad}(y)$-SAP assemblies in the presence of $\beta C D$ (black square) and AdC (red circle). The curves are drawn based on the simplified model we proposed previously ${ }^{37}$. 
(a)
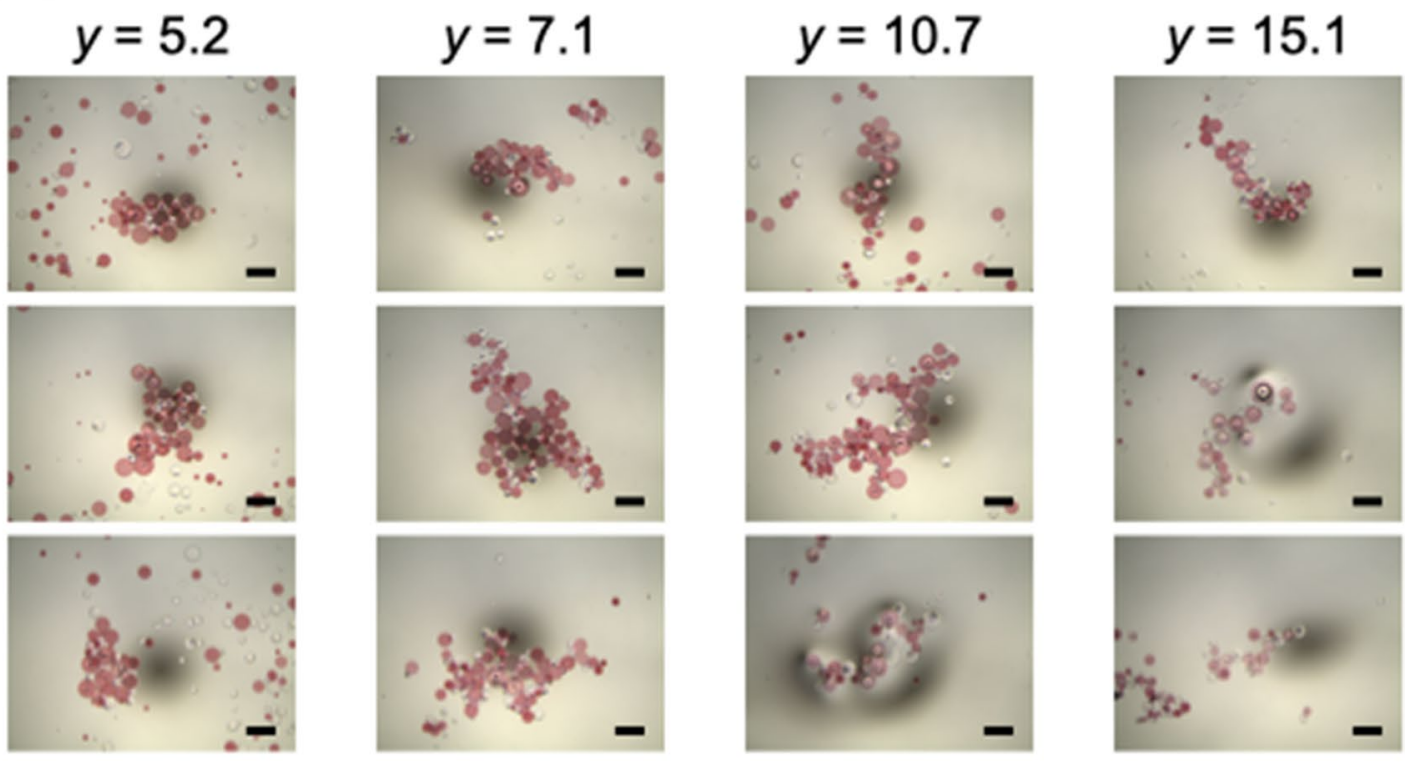

(b)

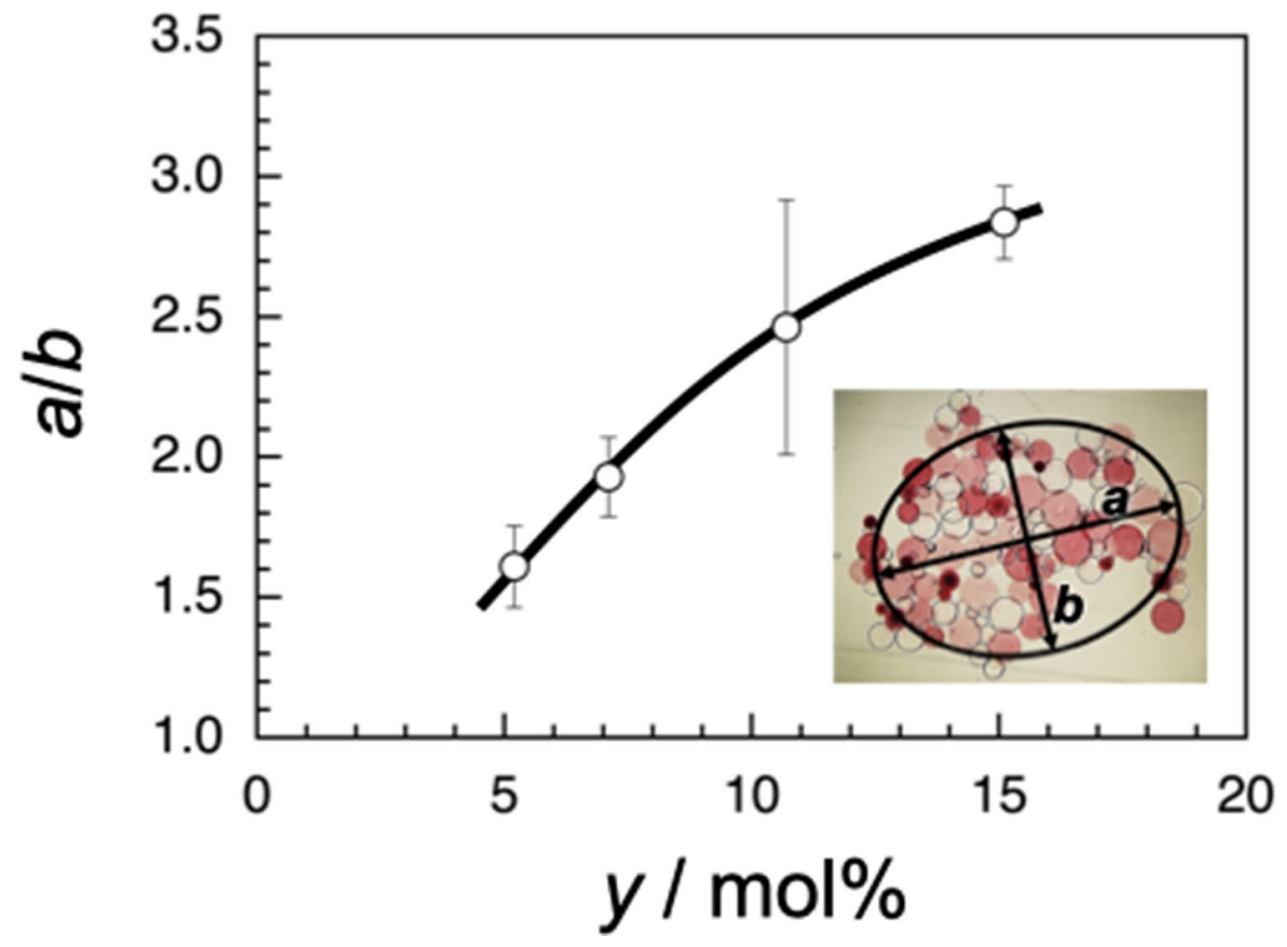

Figure 3. (a) Optical micrographs for assemblies formed from $\beta \mathrm{CD}(26.7)-\mathrm{SAP}$ and $\mathrm{Ad}(y)$-SAP microparticles of $y=5.2,7.1,10.7$, and 15.1. The segments indicate $20 \mu \mathrm{m}$. (b) The aspect ratio, $a / b$, of assemblies as a function of $y$, and a typical example of estimation of $a / b$ using an ImageJ software. The inset is an optical micrograph for the assembly formed from $\beta C D(26.7)$-SAP and Ad(5.2)-SAP microparticles. 
motion. It should be noted here that the SAP microparticles used in this study were rather spherical. Colloidal particle aggregation has been studied in detail for a century or longer ${ }^{39-44}$. The aggregates of colloidal particles often take fractal structures which obey

$$
M \propto R^{D_{\mathrm{f}}}
$$

where $M$ and $R$ are the mass and radius of colloidal aggregate, respectively, and $D_{\mathrm{f}}$ denotes the fractal dimension ${ }^{45-48}$. Colloidal aggregates of larger $D_{\mathrm{f}}$ are denser, whereas aggregates of smaller $D_{\mathrm{f}}$ are less dense. On the basis of simulation and experimental studies on colloidal aggregation, it is known that $D_{\mathrm{f}}$ is ca. 1.75 for aggregates formed through the diffusion-limited aggregation and $D_{\mathrm{f}}$ is ca. 2.05 for those formed through the reaction-limited aggregation ${ }^{49,50}$. In the case of aggregates formed from a number of colloidal particles, the density of aggregates is dependent on $D_{\mathrm{f}}$ but the shape of aggregates is practically independent on $D_{\mathrm{f}}$. Figure 4 indicates colloidal aggregates of $D_{\mathrm{f}}=1.75$ (Fig. 4a,c,e and g) and 2.05 (Fig. 4b,d,f and h) formed from different numbers of particles $\left(N_{c}\right)$ using a Tunable Diffusion Limited Aggregation software ${ }^{51,52}$. As can be seen in this figure, aggregates of $D_{\mathrm{f}}=1.75$ are less dense than those of $D_{\mathrm{f}}=2.05$. It should be noted here that colloidal aggregates formed from 15 particles $\left(N_{c}=15\right)$ can be analyzed by the ellipse fit, whereas, in the cases of $N_{c}=30,100$, and 200, colloidal aggregates take star-shapes and may not be appropriate for the ellipse fit analysis. Using the two-dimensional projections of aggregates of $N_{\mathrm{c}}=15$ (Fig. $4 \mathrm{a}, \mathrm{b}$ ), the $a / b$ values were estimated to be 1.75 and 1.45 for $D_{\mathrm{f}}=1.75$ and 2.05, respectively, with an ImageJ software. Thus, it can be concluded that the $a / b$ ratio is dependent on $D_{\mathrm{f}}$ in the case of aggregates of smaller $N_{\mathrm{c}}$.

Since in the present system of $\beta \mathrm{CD}(x)$-SAP and $\operatorname{Ad}(y)$-SAP microparticles, assemblies are formed through the formation of inclusion complexes of $\beta C D$ and Ad residues, we should also discuss binary colloidal aggregation through attractive interactions, e.g., electrostatic interaction of oppositely-charged colloidal particles ${ }^{53-55}$. In the case of binary colloidal aggregation, it is known that the structure of aggregates is also dependent on the ratio of radii and the ratio of the numbers of colloidal particles of different types ${ }^{56-61}$. In the present study, the ratio of average diameters, $D_{\mathrm{av}}$, was approximately 2 and the ratio of the numbers of particles was set to almost unity. It should be noted here that the randomness of collision is also important. In the system of $\beta C D(x)$-SAP and $\operatorname{Ad}(y)$-SAP microparticles, the collisions of microparticles, i.e., non-Brownian particles, may not be purely random because the mixtures of microparticles were agitated with a mixer. On the basis of these considerations, we can conclude that the assembly of $\beta \mathrm{CD}(x)$-SAP and $\operatorname{Ad}(y)$-SAP microparticles exhibited a strong correlation between $y$ and $a / b$ because of the limited conditions, e.g., the limited number of particles, the ratios of radii and the numbers of microparticles, and the mixing procedure. It may be possible to control the structure of assemblies of $\beta C D(x)$-SAP and Ad $(y)$-SAP microparticles in a different manner under other conditions.

It is important to understand differences and similarities between macroscopic and microscopic assemblies. We believe that this study which compared assemblies of SAP microparticles with colloidal particles should provide significant insights.

\section{Conclusions}

In this study, the self-assembly behavior of $\beta \mathrm{CD}(x)$-SAP and $\operatorname{Ad}(y)$-SAP microparticles was investigated. SAP microparticles were modified with $\beta C D$ and Ad residues by coupling of $\beta C D-\mathrm{NH}_{2}$ and $A d-\mathrm{NH}_{2} \cdot \mathrm{HCl}$ with carboxylic acid residues in SAP microparticles using DMT-MM as a coupling agent. The contents of $\beta C D$ and Ad residues in $\beta \mathrm{CD}(x)$-SAP and $\operatorname{Ad}(y)$-SAP microparticles, $x$ and $y$, were roughly estimated by the weights of remaining $\beta \mathrm{CD}-\mathrm{NH}_{2}$ and $\mathrm{Ad}-\mathrm{NH}_{2} \cdot \mathrm{HCl}$ recovered from the reaction mixtures. The adsorption experiments indicated that $\beta C D$ residues were introduced efficiently not only to carboxylate residues on the surface of SAP microparticles but also to those inside of SAP microparticles, whereas Ad residues were introduced dominantly to carboxylate residues on the outer layer of SAP microparticles. For visual discrimination, $\operatorname{Ad}(y)$-SAP microparticles were dyed with pararosaniline. The interaction of $\beta C D(x)$-SAP and $\operatorname{Ad}(y)$-SAP microparticles was monitored with an optical microscope using aqueous suspension containing ca. 50 microparticles in each on a clean slide glass. Since the SAP microparticles used in this study did not undergo practically Brownian motion because of their larger size, the mixed suspension was agitated at $500 \mathrm{rpm}$ using a mixer to investigate the interaction. $\beta C D(x)$-SAP microparticles of $x=16.2$ or 22.3 did not adhere to any of the $\operatorname{Ad}(y)$-SAP microparticles used in this study, whereas $\beta C D(26.7)-S A P$ microparticles interacted with all the $\operatorname{Ad}(y)$-SAP microparticles examined to form assemblies. These observations indicate that there is a threshold of the $\beta C D$ content in $\beta C D(x)$-SAP microparticles for assembly formation between $x=22.3$ and 26.7. Competitive experiments using $\beta C D$ and AdC as competitors indicated that the formation of assemblies of $\beta C D(26.7)$-SAP and $\operatorname{Ad}(y)$-SAP microparticles was based on the inclusion complex formation between $\beta C D$ and Ad residues on the surface of SAP microparticles, and the interaction of $\beta C D(26.7)$-SAP and $\operatorname{Ad}(y)$-SAP microparticles was stronger at higher $y$. The observation with an optical microscope indicated that the shape of assemblies was dependent on the Ad content, $y$; the aspect ratio $(a / b)$ increased from ca. 1.5 to ca. 2.8 with increasing $y$ from 5.2 to 15.1 . Thus, it can be concluded that the shape of the assemblies is controlled by varying the strength of interaction of $\beta C D(26.7)$-SAP and $\operatorname{Ad}(y)$-SAP microparticles.

\section{Methods}

Materials. Superabsorbent polymer 10SH-NF (SAP) microparticles were kindly supplied from Sumitomo Seika Chemicals Co., Ltd. (Osaka, Japan). Ad- $\mathrm{NH}_{2} \cdot \mathrm{HCl}$ was purchased from Tokyo Chemical Industry Co., Ltd. (Tokyo, Japan). DMT-MM and $\mathrm{D}_{2} \mathrm{O}$ were purchased from FUJIFILM Wako Pure Chemical Corp. (Osaka, Japan). $\beta$ CD was purchased from Junsei Chemical Co., Ltd. (Tokyo, Japan). Pararosaniline was purchased from Nacalai Tesque, Inc. (Kyoto, Japan). $\beta \mathrm{CD}-\mathrm{NH}_{2}$ was prepared by previously reported procedure with slight modification $^{62}$. Other reagents were used without further purification. 


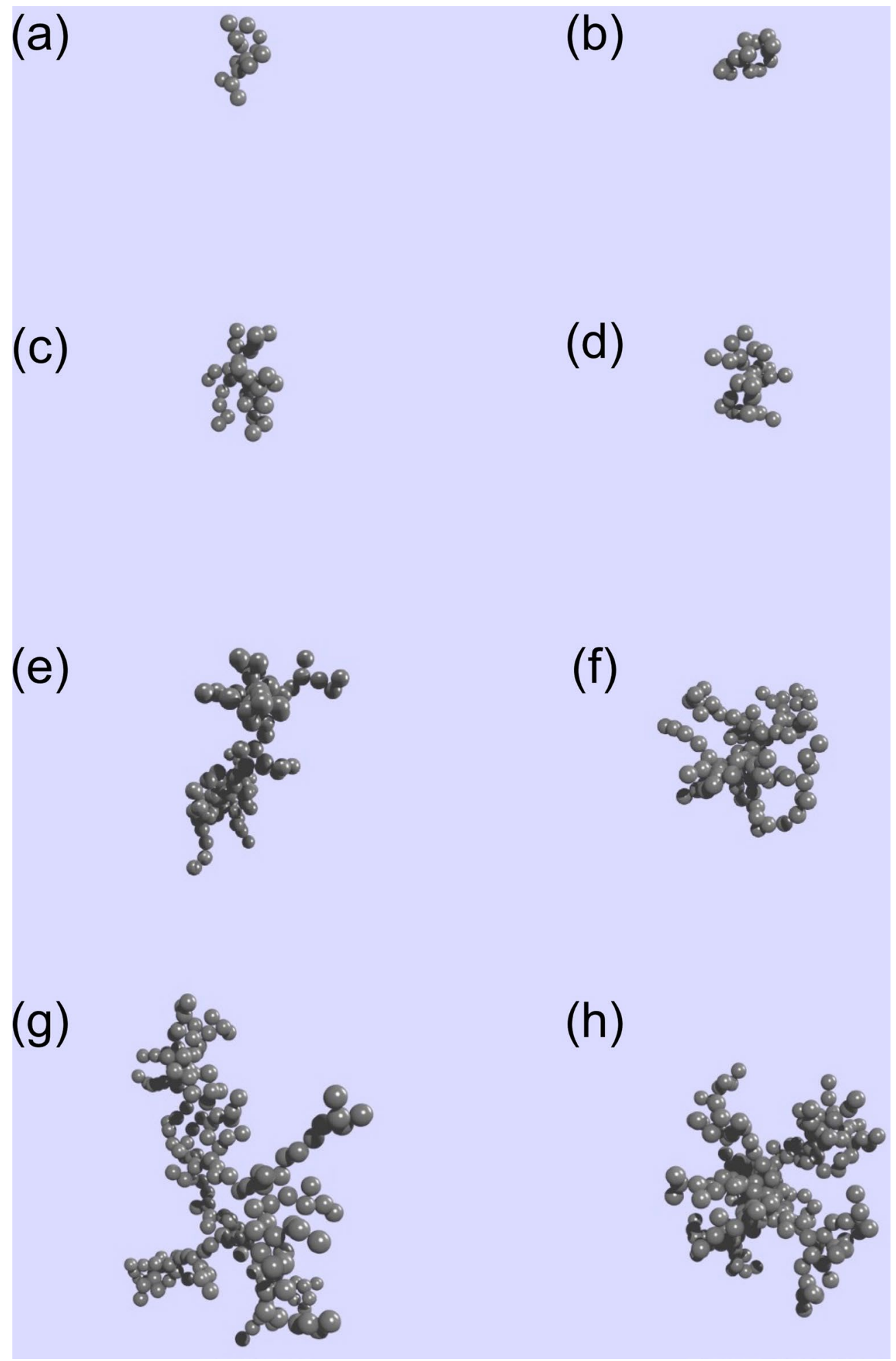

Figure 4. Examples for colloidal aggregates constructed using a tunable diffusion limited aggregation software $^{51,52} . D_{\mathrm{f}}=1.75(\mathbf{a}, \mathbf{c}, \mathbf{e}$, and $\mathbf{g})$ and $2.05(\mathbf{b}, \mathbf{d}, \mathbf{f}$, and $\mathbf{h})$ formed from $15(\mathbf{a}, \mathbf{b}), 30(\mathbf{c}, \mathbf{d}), 100(\mathbf{e}, \mathbf{f})$, and 200 particles (g,h).

Measurements. $\quad{ }^{1} \mathrm{H}$ NMR spectra were recorded on a JEOL JNM ECA500 spectrometer. Chemical shifts were referenced to the solvent values (2.49 and $4.79 \mathrm{ppm}$ for DMSO- $d_{6}$ and $\mathrm{D}_{2} \mathrm{O}$, respectively). Solid-state ${ }^{1} \mathrm{H}$ FGMAS NMR spectra were obtained for the SAP microparticles swollen with $\mathrm{D}_{2} \mathrm{O}$ on a JEOL ECA400 spectrometer. Sample spinning rate was $7 \mathrm{kHz}$. ATR FT/IR spectra were measured on a JASCO FT/IR-6100 spectrometer equipped with a diamond ATR accessory. The FT/IR spectrometer was constantly purged with $\mathrm{N}_{2}$ gas. 
Preparation of $\beta C D(x)$-SAP and Ad(y)-SAP microparticles. $\quad \beta C D(x)$-SAP and $\operatorname{Ad}(y)$-SAP microparticles were prepared by amide coupling of carboxylate residues in the SAP microparticles with $\beta C D-\mathrm{NH}_{2}$ and Ad- $\mathrm{NH}_{2} \cdot \mathrm{HCl}$, respectively, using DMT-MM as a coupling agent in water. Predetermined amounts of SAP microparticles, $\beta \mathrm{CD}-\mathrm{NH}_{2}$ (or Ad- $-\mathrm{NH}_{2} \cdot \mathrm{HCl}$ ) and water were placed in a reaction vessel. After cooling the mixture at $5{ }^{\circ} \mathrm{C}$, an aqueous solution $(10 \mathrm{~mL})$ of a predetermined amount of DMT-MM was added dropwise to the mixture. After agitating for $18 \mathrm{~h}$ at room temperature, the SAP microparticles were recovered by filtration with a glass filter, and the SAP microparticles were thoroughly washed with water to remove impurities soluble in water, i.e., unreacted DMT-MM and $\beta \mathrm{CD}-\mathrm{NH}_{2}$ (or Ad- $\mathrm{NH}_{2} \cdot \mathrm{HCl}$ ) and by-products from DMT-MM. All the washings were collected and combined. After evaporation of the solvent, the residue was measured by ${ }^{1} \mathrm{H}$ NMR to determine the molar ratios of components. Using the molar ratios of components and the weight of residue, the content of $\beta C D$ (or Ad) residue, i.e., $x$ (or $y$ ), was roughly estimated (Tables 1 and 2). Portions of the $\beta C D(x)$-SAP and $\operatorname{Ad}(y)$-SAP microparticles obtained were lyophilized for ${ }^{1} \mathrm{H}$ FGMAS NMR and ATR FT/IR spectroscopy.

For visual discrimination, the $\operatorname{Ad}(y)$-SAP microparticles obtained were dyed by immersing in an aqueous solution of pararosaniline $(0.05 \mathrm{M})$ for $1 \mathrm{~h}$.

Adsorption tests. SAP microparticles fully swollen with water $(2.0 \mathrm{~g})$ were added to an aqueous solution of $\beta \mathrm{CD}-\mathrm{NH}_{2}$ or Ad- $\mathrm{NH}_{2} \cdot \mathrm{HCl}(5.0 \mathrm{mM}, 20 \mathrm{~mL})$ and the mixture was stirred at room temperature $\left(\mathrm{ca} .25^{\circ} \mathrm{C}\right.$ ) for $18 \mathrm{~h}$. After removing the SAP microparticles by filtration, the concentration of solution of $\beta \mathrm{CD}-\mathrm{NH}_{2}$ or Ad- $\mathrm{NH}_{2} \cdot \mathrm{HCl}$ was determined by an Anton-Paar DMA5000 density meter using the calibration curve prepared separately. Using the volume and concentration of solution, the amount of $\beta \mathrm{CD}-\mathrm{NH}_{2}$ or Ad- $\mathrm{NH}_{2} \cdot \mathrm{HCl}$ adsorbed per gram of SAP microparticles swollen was estimated.

Interaction of $\beta C D(x)$-SAP and $\operatorname{Ad}(y)$-SAP microparticles. Suspensions of $\beta C D(x) \operatorname{SAP}$ and $\operatorname{Ad}(y)$ SAP microparticles $(1 \mu \mathrm{L}$ each) were placed and mixed on a glass plate. The mixture was agitated at ca. $500 \mathrm{rpm}$ using an EYELA CM-1000 cute mixer. The assemblies formed were observed on an EVOS optical microscope.

Received: 25 November 2020; Accepted: 8 March 2021

Published online: 18 March 2021

\section{References}

1. Whitesides, G. M. \& Boncheva, M. Beyond molecules: self-assembly of mesoscopic and macroscopic components. Proc. Natl. Acad. Sci. U.S.A. 99, 4769-4774. https://doi.org/10.1073/pnas.082065899 (2002).

2. Harada, A., Takashima, Y. \& Nakahata, M. Supramolecular polymeric materials via cyclodextrin-guest interactions. Acc. Chem. Res. 47, 2128-2140. https://doi.org/10.1021/ar500109h (2014).

3. Mejia-Ariza, R., Graña-Suárez, L., Verboom, W. \& Huskens, J. Cyclodextrin-based supramolecular nanoparticles for biomedical applications. J. Mater. Chem. B 5, 36-52. https://doi.org/10.1039/C6TB02776H (2017).

4. Schneider, H.-J. \& Strongin, R. M. supramolecular interactions in chemomechanical polymers. Acc. Chem. Res. 42, 1489-1500. https://doi.org/10.1021/ar800274u (2009).

5. Schneider, H.-J. Logic-gate functions in chemomechanical materials. ChemPhysChem 18, 2306-2313. https://doi.org/10.1002/ cphc.201700186 (2017).

6. Fasano, V. et al. Organic nanofibers embedding stimuli-responsive threaded molecular components. J. Am. Chem. Soc. 136, 14245-14254. https://doi.org/10.1021/ja5080322 (2014).

7. Takashima, Y. et al. Expansion-contraction of photoresponsive artificial muscle regulated by host-guest interactions. Nat. Commun. 3, 1270. https://doi.org/10.1038/ncomms2280 (2012).

8. Iwaso, K., Takashima, Y. \& Harada, A. Fast response dry-type artificial molecular muscles with [c2] daisy chains. Nat. Chem. 8, 625-632. https://doi.org/10.1038/nchem.2513 (2016).

9. Ikejiri, S., Takashima, Y., Osaki, M., Yamaguchi, H. \& Harada, A. Solvent-free photoresponsive artificial muscles rapidly driven by molecular machines. J. Am. Chem. Soc. 140, 17308-17315. https://doi.org/10.1021/jacs.8b11351 (2018).

10. Haino, T. Molecular-recognition-directed formation of supramolecular polymers. Polym. J. 45, 363-383. https://doi.org/10.1038/ pj.2012.144 (2013).

11. Anderson, C. A. et al. High-affinity DNA base analogs as supramolecular, nanoscale promoters of macroscopic adhesion. J. Am. Chem. Soc. 135, 7288-7295. https://doi.org/10.1021/ja4005283 (2013).

12. Hu, J. \& Liu, S. Engineering responsive polymer building blocks with host-guest molecular recognition for functional applications. Acc. Chem. Res. 47, 2084-2095. https://doi.org/10.1021/ar5001007 (2014).

13. Nakahata, M., Takashima, Y., Yamaguchi, H. \& Harada, A. Redox-responsive self-healing materials formed from host-guest polymers. Nat. Commun. 2, 511. https://doi.org/10.1038/ncomms1521 (2011).

14. Yan, X. et al. A self-healing supramolecular polymer gel with stimuli-responsiveness constructed by crown ether based molecular recognition. Polym. Chem. 4, 3312-3322. https://doi.org/10.1039/C3PY00283G (2013).

15. Chen, S. \& Binder, W. H. Dynamic ordering and phase segregation in hydrogen-bonded polymers. Acc. Chem. Res. 49, 1409-1420. https://doi.org/10.1021/acs.accounts.6b00174 (2016).

16. Kakuta, T. et al. Preorganized hydrogel: self-healing properties of supramolecular hydrogels formed by polymerization of hostguest-monomers that contain cyclodextrins and hydrophobic guest groups. Adv. Mater. 25, 2849-2853. https://doi.org/10.1002/ adma.201205321 (2013).

17. Nakahata, M., Takashima, Y. \& Harada, A. Highly flexible, tough, and self-healing supramolecular polymeric materials using host-guest interaction. Macromol. Rapid Commun. 37, 86-92. https://doi.org/10.1002/marc.201500473 (2016).

18. Nakahata, M., Mori, S., Takashima, Y., Yamaguchi, H. \& Harada, A. Self-healing materials formed by cross-linked polyrotaxanes with reversible bonds. Chem 1, 766-775. https://doi.org/10.1016/j.chempr.2016.09.013 (2016).

19. McKee, J. R. et al. Healable, stable and stiff hydrogels: combining conflicting properties using dynamic and selective three-component recognition with reinforcing cellulose nanorods. Adv. Funct. Mater. 24, 2706-2713. https://doi.org/10.1002/adfm.20130 3699 (2014). 
20. Liu, J., Soo Yun Tan, C., Lan, Y. \& Scherman, O. A. Toward a versatile toolbox for cucurbit $[n]$ uril-based supramolecular hydrogel networks through in situ polymerization. J. Polym. Sci. Part A Polym. Chem. 55, 3105-3109. https://doi.org/10.1002/pola.28667 (2017).

21. Liu, J., Tan, C. S. Y. \& Scherman, O. A. Dynamic interfacial adhesion through cucurbit $[n]$ uril molecular recognition. Angew. Chem. Int. Ed. 57, 8854-8858. https://doi.org/10.1002/anie.201800775 (2018).

22. Wang, T., Yu, X., Li, Y., Ren, J. \& Zhen, X. Robust, self-healing, and multistimuli-responsive supergelator for the visual recognition and separation of short-chain cycloalkanes and alkanes. ACS Appl. Mater. Interfaces 9, 13666-13675. https://doi.org/10.1021/ acsami.6b15249 (2017).

23. Wang, Z. et al. A Rapidly self-healing host-guest supramolecular hydrogel with high mechanical strength and excellent biocompatibility. Angew. Chem. Int. Ed. 57, 9008-9012. https://doi.org/10.1002/anie.201804400 (2018).

24. Jia, Y.-G. et al. Self-healing hydrogels of low molecular weight poly(vinyl alcohol) assembled by host-guest recognition. Biomacromol 19, 626-632. https://doi.org/10.1021/acs.biomac.7b01707 (2018).

25. Yu, C., Alkekhia, D. \& Shukla, A. $\beta$-Lactamase responsive supramolecular hydrogels with host-guest self-healing capability. ACS Appl. Polym. Mater. 2, 55-65. https://doi.org/10.1021/acsapm.9b00879 (2020).

26. Harada, A., Kobayashi, R., Takashima, Y., Hashidzume, A. \& Yamaguchi, H. Macroscopic self-assembly through molecular recognition. Nat. Chem. 3, 34-37. https://doi.org/10.1038/nchem.893 (2011).

27. Yamaguchi, H., Kobayashi, R., Takashima, Y., Hashidzume, A. \& Harada, A. Self-assembly of gels through molecular recognition of cyclodextrins: shape selectivity for linear and cyclic guest molecules. Macromolecules 44, 2395-2399. https://doi.org/10.1021/ ma200398y (2011).

28. Cheng, M. et al. Macroscopic supramolecular assembly of rigid building blocks through a flexible spacing coating. Adv. Mater. 26, 3009-3013. https://doi.org/10.1002/adma.201305177 (2014).

29. Xiao, M., Xian, Y. \& Shi, F. Precise macroscopic supramolecular assembly by combining spontaneous locomotion driven by the marangoni effect and molecular recognition. Angew. Chem. Int. Ed. 54, 8952-8956. https://doi.org/10.1002/anie.201502349 (2015).

30. Akram, R., Arshad, A., Wu, Y., Wu, Z. \& Wu, D. Efficient modification with flexible spacing coating for in situ reversible assembly of semirigid macroscopic objects through hierarchical metal coordination. Polym. Adv. Technol. 29, 226-233. https://doi.org/10. 1002/pat.4107 (2018).

31. Zheng, Y., Hashidzume, A., Takashima, Y., Yamaguchi, H. \& Harada, A. Macroscopic observation of molecular recognition: discrimination of the substituted position on naphthyl group by polyacrylamide gel modified with $\beta$-cyclodextrin. Langmuir 27, 13790-13795. https://doi.org/10.1021/la2034142 (2011).

32. Hashidzume, A., Zheng, Y., Takashima, Y., Yamaguchi, H. \& Harada, A. Macroscopic self-assembly based on molecular recognition: effect of linkage between aromatics and the polyacrylamide gel scaffold, amide versus ester. Macromolecules 46, 1939-1947. https://doi.org/10.1021/ma302344x (2013).

33. Zheng, Y. et al. Visible chiral discrimination via macroscopic selective assembly. Commun. Chem. 1, 4. https://doi.org/10.1038/ s42004-017-0003-x (2018).

34. Watanabe, Y., Fuji, T., Hioki, K., Tani, S. \& Kunishima, M. Development of a Simple system for dehydrocondensation using solidphase adsorption of a water-soluble dehydrocondensing reagent (DMT-MM). Chem. Pharm. Bull. 52, 1223-1226. https://doi.org/ 10.1248/cpb.52.1223 (2004).

35. He, Y., Fu, P., Shen, X. \& Gao, H. Cyclodextrin-based aggregates and characterization by microscopy. Micron 39, 495-516. https:// doi.org/10.1016/j.micron.2007.06.017 (2008).

36. Tomatsu, I., Hashidzume, A. \& Harada, A. Cyclodextrin-based side chain polyrotaxane with unidirectional inclusion in aqueous media. Angew. Chem. Int. Ed. 45, 4605-4608. https://doi.org/10.1002/anie.200601081 (2006).

37. Hashidzume, A., Itami, T., Kamon, Y. \& Harada, A. A simplified model for multivalent interaction competing with a low molecular weight competitor. Chem. Lett. 49, 1306-1308 (2020).

38. Rasband, W.S. ImageJ (U. S. National Institutes of Health, Bethesda, Maryland, USA, 1997-2014).

39. von Smoluchowski, M. Mathematical theory of the kinetics of the coagulation of colloidal solutions. Z. Phys. Chem. 92, 129-168 (1917).

40. Hidalgo-Álvarez, R. et al. Electrokinetic properties, colloidal stability and aggregation kinetics of polymer colloids. Adv. Colloid Interface Sci. 67, 1-118. https://doi.org/10.1016/0001-8686(96)00297-7 (1996).

41. Dickinson, E. Structure and rheology of simulated gels formed from aggregated colloidal particles. J. Colloid Interface Sci. 225, 2-15. https://doi.org/10.1006/jcis.1999.6662 (2000).

42. Zhou, J., Ralston, J., Sedev, R. \& Beattie, D. A. Functionalized gold nanoparticles: Synthesis, structure and colloid stability. J. Colloid Interface Sci. 331, 251-262. https://doi.org/10.1016/j.jcis.2008.12.002 (2009).

43. Lu, Z. \& Yin, Y. Colloidal nanoparticle clusters: functional materials by design. Chem. Soc. Rev. 41, 6874-6887. https://doi.org/10. 1039/C2CS35197H (2012).

44. Szilagyi, I., Trefalt, G., Tiraferri, A., Maroni, P. \& Borkovec, M. Polyelectrolyte adsorption, interparticle forces, and colloidal aggregation. Soft Matter 10, 2479-2502. https://doi.org/10.1039/C3SM52132J (2014).

45. Sander, L. M. Fractal growth processes. Nature 322, 789-793 (1986).

46. Meakin, P. Fractal aggregates. Adv. Colloid Interface Sci. 28, 249-331. https://doi.org/10.1016/0001-8686(87)80016-7 (1987).

47. Meakin, P. Models for colloidal aggregation. Annu. Rev. Phys. Chem. 39, 237-267. https://doi.org/10.1146/annurev.pc.39.100188. 001321 (1988).

48. Kopelman, R. Fractal reaction kinetics. Science 241, 1620-1626. https://doi.org/10.1126/science.241.4873.1620 (1988).

49. Weitz, D. \& Oliveria, M. fractal structures formed by kinetic aggregation of aqueous gold colloids. Phys. Rev. Lett. 52, 1433-1436. https://doi.org/10.1103/PhysRevLett.52.1433 (1984).

50. Weitz, D. A., Huang, J. S., Lin, M. Y. \& Sung, J. Limits of the fractal dimension for irreversible kinetic aggregation of gold colloids. Phys. Rev. Lett. 54, 1416-1419. https://doi.org/10.1103/PhysRevLett.54.1416 (1985).

51. Onofri, F. R. A., Wozniak, M. \& Barbosa, S. On the optical characterisation of nanoparticle and their aggregates in plasma systems. Contrib. Plasma Phys. 51, 228-236. https://doi.org/10.1002/ctpp.201000056 (2011).

52. Wozniak, M., Onofri, F. R. A., Barbosa, S., Yon, J. \& Mroczka, J. Comparison of methods to derive morphological parameters of multi-fractal samples of particle aggregates from TEM images. J. Aerosol Sci. 47, 12-26. https://doi.org/10.1016/j.jaerosci.2011. 12.008 (2012).

53. Varga, I., Kun, F. \& Pál, K. Structure formation in binary colloids. Phys. Rev. E 69, 030501. https://doi.org/10.1103/PhysRevE.69. $030501(2004)$

54. Lopez-Lopez, J. M., Schmitt, A., Moncho-Jorda, A. \& Hidalgo-Alvarez, R. Stability of binary colloids: kinetic and structural aspects of heteroaggregation processes. Soft Matter 2, 1025-1042. https://doi.org/10.1039/B608349H (2006).

55. Dickinson, E. Stabilising emulsion-based colloidal structures with mixed food ingredients. J. Sci. Food Agric. 93, 710-721. https:// doi.org/10.1002/jsfa.6013 (2013)

56. Hiddessen, A. L., Rodgers, S. D., Weitz, D. A. \& Hammer, D. A. Assembly of binary colloidal structures via specific biological adhesion. Langmuir 16, 9744-9753. https://doi.org/10.1021/la000715f (2000).

57. Ristenpart, W., Aksay, I. \& Saville, D. Electrically guided assembly of planar superlattices in binary colloidal suspensions. Phys. Rev. Lett. 90, 128303. https://doi.org/10.1103/PhysRevLett.90.128303 (2003). 
58. Pierce, F., Chakrabarti, A., Fry, D. \& Sorensen, C. M. Computer simulation of selective aggregation in binary colloids. Langmuir 20, 2498-2502. https://doi.org/10.1021/la0356452 (2004).

59. Stirner, T. \& Sun, J. Molecular dynamics simulation of the structural configuration of binary colloidal monolayers. Langmuir 21, 6636-6641. https://doi.org/10.1021/la050402q (2005).

60. Rabideau, B. D. \& Bonnecaze, R. T. Computational predictions of stable 2D arrays of bidisperse particles. Langmuir 21, 1085610861. https://doi.org/10.1021/la050462w (2005).

61. Law, A. D., Auriol, M., Smith, D., Horozov, T. S. \& Buzza, D. M. A. Self-assembly of two-dimensional colloidal clusters by tuning the hydrophobicity, composition, and packing geometry. Phys. Rev. Lett. 110, 138301. https://doi.org/10.1103/PhysRevLett.110. 138301 (2013).

62. Hamasaki, K. et al. Fluorescent sensors of molecular recognition. Modified cyclodextrins capable of exhibiting guest-responsive twisted intramolecular charge transfer fluorescence. J. Am. Chem. Soc. 115, 5035-5040. https://doi.org/10.1021/ja00065a012 (1993).

\section{Acknowledgements}

The authors express their acknowledgment to Dr. Naoya Inazumi, Graduate School of Science, Osaka University, for FGMAS NMR measurements.

\section{Author contributions}

A. Harada supervised the project; T.I., A. Hashidzume, H.Y., and A. Harada designed the project; T.I. and A. Hashidzume, Y.K. performed the experiments; T.I., A. Hashidzume, Y.K. analyzed data; all the authors discussed the results; A. Hashidzume and A. Harada wrote the paper.

\section{Competing interests}

The authors declare no competing interests.

\section{Additional information}

Supplementary Information The online version contains supplementary material available at https://doi.org/ 10.1038/s41598-021-85816-Z.

Correspondence and requests for materials should be addressed to A.H. or A.H.

Reprints and permissions information is available at www.nature.com/reprints.

Publisher's note Springer Nature remains neutral with regard to jurisdictional claims in published maps and institutional affiliations.

(c) (i) Open Access This article is licensed under a Creative Commons Attribution 4.0 International License, which permits use, sharing, adaptation, distribution and reproduction in any medium or format, as long as you give appropriate credit to the original author(s) and the source, provide a link to the Creative Commons licence, and indicate if changes were made. The images or other third party material in this article are included in the article's Creative Commons licence, unless indicated otherwise in a credit line to the material. If material is not included in the article's Creative Commons licence and your intended use is not permitted by statutory regulation or exceeds the permitted use, you will need to obtain permission directly from the copyright holder. To view a copy of this licence, visit http://creativecommons.org/licenses/by/4.0/.

(c) The Author(s) 2021 